\title{
Assessment of the influence of micro- and nano-silica on the behavior of self-compacting lightweight concrete using full factorial design
}

\author{
Oveys Afzali-Naniz ${ }^{1} \cdot$ Moosa Mazloom $^{1}$
}

Received: 17 May 2018 / Accepted: 1 October 2018 / Published online: 6 October 2018

(c) The Author(s) 2018

\begin{abstract}
The effects of different replacement levels of micro-silica (MS), colloidal nano-silica (CS) and also the combined addition of MS and CS on the behavior of self-compacting lightweight concrete (SCLC) were studied using the general full factorial design method. Three factors, including water to binder ratio $(w / b)$ with two levels of 0.35 and 0.45 , CS with four replacement levels of $0,1,3$ and 5\%, and MS with two replacement levels of $0 \%$ and $10 \%$ were chosen and three tests were conducted for each response. The modulus of elasticity, compressive strength and water absorption were selected as the responses at the age of 28 days. Also, using multiple regression analysis, acceptable prediction regression models were derived. The analysis of variance (ANOVA) showed that the effects of all three factors on fresh and hardened properties of SCLCs were significant. The results displayed that the mentioned properties for the SCLC specimens containing MS or CS improved, but the best performance was obtained in ternary mixes which were created by adding both MS and CS simultaneously. The optimal condition for having the best result of SCLC was obtained when the amounts of MS and CS were $10 \%$ and $3 \%$, respectively.
\end{abstract}

Keywords Optimization $\cdot$ Factorial design $\cdot$ Self-compacting lightweight concrete $\cdot$ Colloidal nano-silica $\cdot$ Modulus of elasticity $\cdot$ Water absorption

\section{Introduction}

Self-compacting lightweight concrete (SCLC) is defined as a category of high-performance concrete that combines the desirable properties of self-compacting concrete (SCC) and lightweight concrete (LWC) (Wu et al. 2009; Mazloom and Mahboubi 2017). SCLC can spread into place and be compacted in dense reinforced formworks, while segregation or bleeding does not occur (Ranjbar and Mousavi 2015). Moreover, because of the ability to reduce dead loads, using SCLC can be favorable for structures. Properties such as the compressive strength and durability of SCLC are comparable to normal weight self-compacting concrete (NWSCC) (Lachemi et al. 2009). Therefore, the technical, environmental and economic advantages of SCLC encourage researchers to pay more attention to the significant features of this kind

Moosa Mazloom

mazloom@sru.ac.ir

Oveys Afzali-Naniz

oveys.afzali@sru.ac.ir

1 Department of Civil Engineering, Shahid Rajaee Teacher Training University, Lavizan, Tehran, Iran of concrete (Mazloom et al. 2017, 2018; Karamloo et al. 2016b, 2017; Salehi and Mazloom 2018a, b; Afzali-Naniz and Mazloom 2018; Mazloom and Yoosefi 2013).

In recent years, the special effects of different admixtures on the properties of NWSCC have been investigated. Many researchers have concentrated on the use of cementitious materials as partial replacements of cement to advance the rheological, mechanical and durability of NWSCC. In fact, to accomplish high-performance self-compacting concrete, it is required to use microscale or nanoscale of mineral admixtures (Bernal et al. 2018). In microscale, micro-silica (MS) is a popular pozzolan (Mazloom et al. 2004, 2015), and nanosilica is the most widely used nanoparticle for producing cement-based materials (Singh et al. 2013). The strength of mortar and concrete can be enhanced by nano-silica in different ways including (Hosseinpourpia et al. 2012; Bahadori and Hosseini 2012; Hosseini et al. 2010): controlling crystallization which prevents the crystallization of weak crystals such as ettringite and calcium hydroxide; benefiting from the micro-filling effect of nano-silica particles which causes them to fill small voids; creating a calcium-silicate-hydrate (C-S-H) dense gel, which changes the weak crystals into strong ones; benefiting from the nucleus-like act, which 
makes the nanoparticles create bonds due to their highly specific surface area. Nano-silica can be used in the form of dry powder or colloidal suspension. In fact, colloidal suspension can provide a better dispersion of the particles, so in comparison with the powder form it is more efficient and much easier to use (Mukharjee and Barai 2014; Chithra et al. 2016).

Few studies have been performed to investigate the properties of NWSCC containing micro-/nano-silica. Bernal et al. (2018) studied the effects of micro- and nano-silica as an extra cementitious material, and not as a cement replacement material, on the fresh and mechanical properties of NWSCC. Jalal et al. (2015) investigated the effects of some admixtures including fly ash, nano-silica and micro-silica on the behavior of high-performance self-compacting concrete (HPSCC). They reported that the strength properties improved via the blend of mineral admixtures and nanopowders. Also, Puentes et al. (2015) reported that silica-based micro and nano additions improved NWSCC performance at early ages with respect to the chemical reaction and the structure development.

However, researches on self-compacting lightweight concrete have been far less than those on normal weight self-compacting concrete. The importance of SCLC cannot be neglected due to its remarkable benefits for many applications and structures. Also, it should be mentioned that benefiting from all aspects of this material requires a deep understanding of its performance. In all these few researches that have been done on self-compacting lightweight concrete, various parameters of this concrete have been investigated (Güneyisi et al. 2015, 2016; Karamloo et al. 2016a), but still there are parameters that have not been discussed. SCLC may have different behavior in comparison with normal concrete (NC) and NWSCC due to different materials such as the type of aggregate and the volume of paste. Moreover, it is obvious that compressive strength is an important mechanical property, but it is worth noting that the modulus of elasticity is also another vital property that affects the service life, durability and safety of the concrete structures (Parra et al. 2011).

Factorial design method is an applicable technique due to its benefits such as reducing the number of experiments, being time saving and being effective in reducing the cost of the overall research. In fact, this technique is a method of distinguishing the factors with significant effects on a response as well as distinguishing how the effects of one factor differ based on the level of others (Ashenai Ghasemi et al. 2017). In this paper, the general full factorial design technique is used considering parameters such as $W / b$ ratio, CS (\%) and MS (\%) for analyzing their effects on the compressive strength, the modulus of elasticity and water absorption of SCLC. According to the analysis of variance (ANOVA), the key parameters affecting the mentioned properties were determined and appropriate prediction regression models were obtained. Furthermore, the effects of each parameter on the mentioned properties were discussed and the optimal value of all the factors was found.

\section{Experimental program}

\section{Materials}

Type I-425 Portland cement (CEM I 42.5 N) was used in this investigation. As previously stated, nano-silica can be found commercially in dry form and colloidal form. Colloidal nanosilica denotes small particles (less than $100 \mathrm{~nm}$ ) consisting of amorphous $\mathrm{SiO}_{2}$ (Kong et al. 2015). In this study, colloidal nano-silica (CS) made by Isatis Company (Iran) and commercial micro-silica (MS) provided by Ferro-Alloys Factory (Iran) were used as cement replacement materials. Table 1 shows the technical characteristics of CS. Also, Table 2 shows the chemical properties of the cement and micro-silica. Transmission electron microscope (TEM) was utilized for characterization of CS particles. The obtained TEM pictures of CS is shown in Fig. 1. Also, X-ray diffraction (XRD) analysis of MS is shown in Fig. 2. Light-expanded clay aggregate (LECA) was provided to use as coarse aggregate. The maximum nominal size of the LECA was $12.5 \mathrm{~mm}$. Crushed natural river sand was used as the fine aggregate with the fineness modulus of about 3. To achieve the desired workability of the mixes, a polycarboxylate-based superplasticizer (SP) was used.

\section{Mix proportions and test specimens}

The mix proportions of SCLC are presented in Table 3.

In this study, two series of mixtures with two water/binder ratios of 0.35 and 0.45 were used. In other words, both high and low strength SCLC were used. Each series included eight different mix compositions with different contributions of CS and MS. The percentages of CS which replaced cement were $0,1,3$ and $5 \%$, and the percentages of MS that replaced cement were $0 \%$ and $10 \%$. It is worth mentioning that based on the design of the experiments, all cases of binary (cement + micro-silica or cement + nano-silica) and ternary (cement + micro-silica + nano-silica) mixtures were considered. The mixing procedure involved four main steps including: premixing CS with half of mixing water and then continue mixing to achieve a uniform dispersion of nanoparticles; (2) mixing the powder material (cement, limestone and MS) and the aggregate (LECA and sand) for $1 \mathrm{~min}$ in a drum mixer; (3)

Table 1 Technical characteristics of colloidal nano-silica

\begin{tabular}{llllll}
\hline Color & $\begin{array}{l}\text { Specific } \\
\text { gravity }\end{array}$ & $\begin{array}{l}\text { Solid } \\
\text { content }\end{array}$ & $\begin{array}{l}\text { Particle } \\
\text { size }\end{array}$ & $\begin{array}{l}\text { Thermal } \\
\text { stability }\end{array}$ & PH value \\
\hline White & $1.2 \mathrm{~g} / \mathrm{cm}^{3}$ & $30 \%$ & $10-20 \mathrm{~nm}$ & $5-35^{\circ} \mathrm{C}$ & $9-10.5$ \\
\hline
\end{tabular}


Table 2 Chemical analysis of cement and micro-silica

\begin{tabular}{llllllllllll}
\hline Component (\%) & $\mathrm{SiO}_{2}$ & $\mathrm{Al}_{2} \mathrm{O}_{3}$ & $\mathrm{Fe}_{2} \mathrm{O}_{3}$ & $\mathrm{CaO}$ & $\mathrm{MgO}$ & $\mathrm{SO}_{3}$ & $\mathrm{Na}_{2} \mathrm{O}$ & $\mathrm{K}_{2} \mathrm{O}$ & CI & L.O.I & Residue \\
\hline Cement & 21.32 & 3.83 & 2.96 & 62.02 & 3.44 & 2.09 & 0.42 & 0.71 & 0.04 & 2.4 & 0.77 \\
Micro-silica & 91.7 & 1.2 & 1.1 & 1.7 & 0.9 & 0.2 & 0.5 & 0.7 & - & 2 & - \\
\hline
\end{tabular}

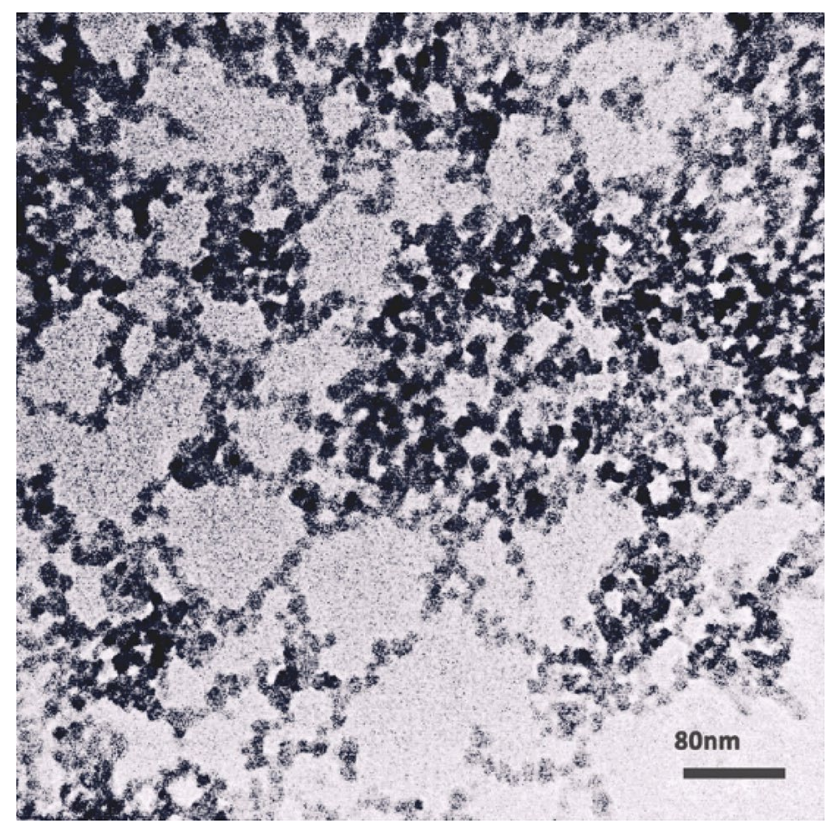

Fig. 1 TEM of colloidal nano-silica

adding CS, which was mixed in water, to a drum mixer and continue mixing for $1 \mathrm{~min}$; (4) adding the mixture of water and superplasticizer to the composition and continue mixing for 5 min to accomplish a fully blended mix. For modulus of elasticity, a cylindrical mold of size $150 \times 300 \mathrm{~mm}$, and for compressive strength and water absorption, cube molds of size $100 \times 100 \times 100 \mathrm{~mm}$ were cast. A wet gunny bag covered up all the molds. After being de-molded, all the concrete specimens were cured under water at $20 \pm 2{ }^{\circ} \mathrm{C}$ until the age of 28 days. The compressive strength and the modulus of elasticity were determined according to BS EN 12390 (2000) and ASTM C469 (2002), respectively. Moreover, to measure the amount of water absorbed by hardened SCLC, the water absorption test was performed according to ASTM C642 (2006). The absorption percentage was calculated by the following equation:

Absorption percentage after immersion $=\frac{B-A}{A} \times 100$,

where $B$ is the mass of the oven-dried sample and $A$ is the mass of surface-dry sample in air after immersion.

\section{Design of experiments}

Factorial design of experiments (DOE) is an effective method of experimentation with the possibility for all factors to differ at the same time over various sets of experimental runs (Montgomery 2017). In this paper, the general full factorial design was used to develop the design of the experiments. The input factors, namely CS (\%), MS (\%) and $w / b$, were considered at two, two and four levels, respectively. For each level, three replicates were carried out. The 16 different compositions were analyzed by Minitab statistical software.

\section{Results and discussion}

\section{Fresh properties}

Table 4 shows the results of fresh properties of SCLCs. Slump flow (time and diameter), J-ring, U-box and V-funnel flow time tests were done on the fresh concrete according
Fig. 2 XRD analysis of microsilica

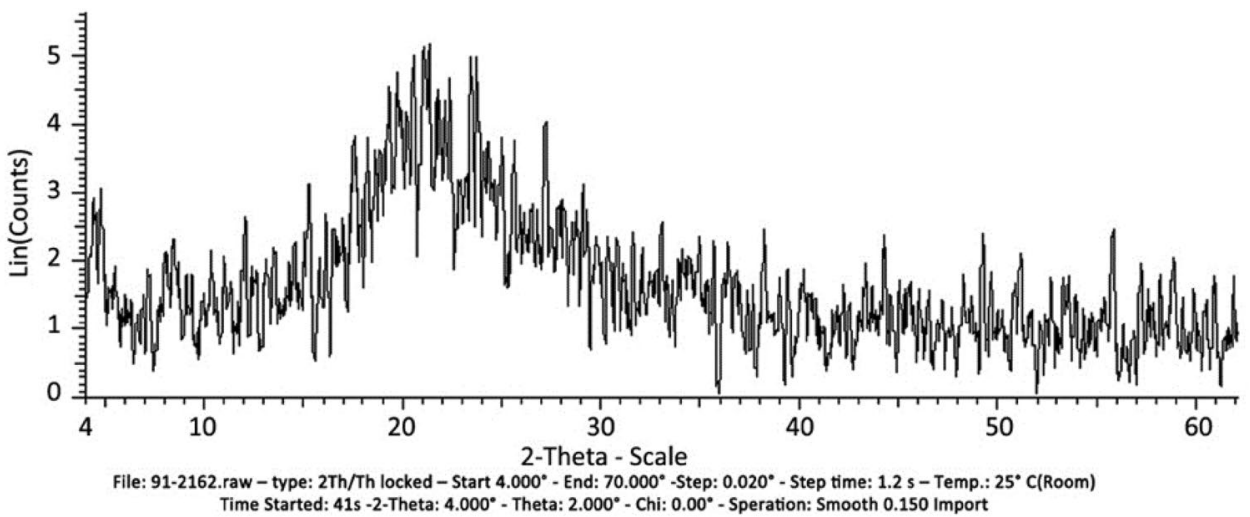


Table 3 The mix proportions of SCLC for factorial design optimization

\begin{tabular}{|c|c|c|c|c|c|c|c|c|c|}
\hline Mixture & $w / b$ & Cement $\left(\mathrm{kg} / \mathrm{m}^{3}\right)$ & MS (\%) & CS (\%) & LECA $\left(\mathrm{kg} / \mathrm{m}^{3}\right)$ & Powder $\left(\mathrm{kg} / \mathrm{m}^{3}\right)$ & $\begin{array}{l}\text { Free water } \\
\left(\mathrm{kg} / \mathrm{m}^{3}\right)\end{array}$ & Sand $\left(\mathrm{kg} / \mathrm{m}^{3}\right)$ & $\mathrm{SP}\left(\mathrm{kg} / \mathrm{m}^{3}\right)$ \\
\hline L-M0C0 & 0.35 & 450 & 0 & 0 & 270 & 230 & 157.5 & 800 & 9 \\
\hline L-M0C1 & 0.35 & 445.5 & 0 & $1 \%$ & 270 & 230 & 157.5 & 800 & 9.45 \\
\hline L-M0C3 & 0.35 & 436.5 & 0 & $3 \%$ & 270 & 230 & 157.5 & 800 & 11.7 \\
\hline L-M0C5 & 0.35 & 427.5 & 0 & $5 \%$ & 270 & 230 & 157.5 & 800 & 13.5 \\
\hline L-M10C0 & 0.35 & 405 & $10 \%$ & 0 & 270 & 230 & 157.5 & 800 & 10.8 \\
\hline L-M10C1 & 0.35 & 400.5 & $10 \%$ & $1 \%$ & 270 & 230 & 157.5 & 800 & 12.15 \\
\hline L-M10C3 & 0.35 & 391.5 & $10 \%$ & $3 \%$ & 270 & 230 & 157.5 & 800 & 14.4 \\
\hline L-M10C5 & 0.35 & 382.5 & $10 \%$ & $5 \%$ & 270 & 230 & 157.5 & 800 & 16.2 \\
\hline H-MOC0 & 0.45 & 400 & 0 & 0 & 270 & 230 & 180 & 800 & 3.6 \\
\hline H-M0C1 & 0.45 & 396 & 0 & $1 \%$ & 270 & 230 & 180 & 800 & 4.05 \\
\hline H-M0C3 & 0.45 & 388 & 0 & $3 \%$ & 270 & 230 & 180 & 800 & 5.85 \\
\hline H-M0C5 & 0.45 & 380 & 0 & $5 \%$ & 270 & 230 & 180 & 800 & 7.2 \\
\hline $\mathrm{H}-\mathrm{M} 10 \mathrm{C} 0$ & 0.45 & 360 & $10 \%$ & $0 \%$ & 270 & 230 & 180 & 800 & 4.5 \\
\hline H-M10C1 & 0.45 & 356 & $10 \%$ & $1 \%$ & 270 & 230 & 180 & 800 & 5.4 \\
\hline H-M10C3 & 0.45 & 348 & $10 \%$ & $3 \%$ & 270 & 230 & 180 & 800 & 7.65 \\
\hline H-M10C5 & 0.45 & 340 & $10 \%$ & $5 \%$ & 270 & 230 & 180 & 800 & 9 \\
\hline
\end{tabular}

Table 4 The fresh properties of SCLC

\begin{tabular}{llllll}
\hline Mix & $\begin{array}{l}\text { Slump } \\
\text { flow } \\
(\mathrm{mm})\end{array}$ & T50 (s) & $\begin{array}{l}\text { J-ring } \\
(\mathrm{mm})\end{array}$ & $\begin{array}{l}\text { V-funnel } \\
(\mathrm{s})\end{array}$ & $\begin{array}{l}\text { U-box (h2- } \\
\text { h1) }(\mathrm{mm})\end{array}$ \\
\hline L-M0C0 & 720 & 3.6 & 665 & 9 & 14 \\
L-M0C1 & 705 & 3.8 & 600 & 10.8 & 18 \\
L-M0C3 & 690 & 4.8 & 610 & 9.5 & 20 \\
L-M0C5 & 625 & 4.7 & 560 & 11.8 & 35 \\
L-M10C0 & 700 & 4 & 615 & 8.6 & 25 \\
L-M10C1 & 710 & 4.6 & 590 & 11.2 & 25 \\
L-M10C3 & 605 & 5.4 & 520 & 15.1 & 36 \\
L-M10C5 & 560 & 6.5 & 480 & 15.3 & 40 \\
H-M0C0 & 785 & 2.3 & 690 & 5.4 & 5 \\
H-M0C1 & 750 & 3.5 & 645 & 6.8 & 10 \\
H-M0C3 & 770 & 3.2 & 640 & 8.4 & 16 \\
H-M0C5 & 650 & 4.5 & 580 & 10.7 & 25 \\
H-M10C0 & 755 & 3 & 635 & 6.3 & 15 \\
H-M10C1 & 715 & 4.9 & 600 & 9.6 & 17 \\
H-M10C3 & 650 & 4.3 & 550 & 10.7 & 22 \\
H-M10C5 & 625 & 5 & 535 & 12.5 & 30 \\
\hline
\end{tabular}

to the "Specification and guidelines for SCC" prepared by EFNARC (2002). In Table 4, the slump flow diameter displays the flowability, and the slump flow time shows the time in which SCLCs reach a diameter of $500 \mathrm{~mm}$. The V-funnel test is used to evaluate the filling ability and viscosity of the produced SCLCs. J-ring test determines the passing ability of the SCLCs through heavy reinforcement. The U-box height method is used to assess the passing and the filling ability of the produced SCLCs in the congested reinforcement. As can be seen in Table 4, in the SCLC mixtures produced in this research, the slump flow diameter was in the range of 560-785 mm, the slump flow time was in the range of 2.3-6.5 s, the J-ring diameter was in the range of 480-690 mm, the V-funnel flow time was in the range of 5.4-15.3 s and finally the U-box height (h2-h1) was between 5 and $40 \mathrm{~mm}$. The required dosage of SP to obtain the aimed fresh properties of SCLCs is given in Table 3. It is clear that the SP content decreases as $w / b$ level changes from the low (0.35) to the high (0.45) level. This can be justified as: by increasing the $w / b$ ratio, the available free water increased and the required dosage of SP decreased. The same behavior has been stated in previous studies (Güneyisi et al. 2016; Felekoglu and Türkel 2007). When the $w / b$ ratio was kept constant, the replacement of cement with MS and CS led to an increase in the dosage of SP and this increase depends on the replacement level of MS and CS. The combined addition of MS and CS, ternary mixtures, needs higher amount of SP to gain the desired workability. These findings are in agreement with previous studies (Bernal et al. 2018; Güneyisi et al. 2016). This issue can be due to the high specific surface of MS and CS. It was observed that the use of both MS and CS decreased the slump flow and J-ring diameter and as a result decreased the flowability and the passing ability of SCLCs. These results are in agreement with Bernal et al. (2018). The increase in CS and MS contents increased the cohesiveness and viscosity of mixes and consequently increased the V-funnel time and U-box height. Nearly all of the SCLCs of this research satisfied the requirements of EFNARC (2002). 
An effective way to recognize the effects of an independent variable on the dependent variable is through the analysis of variance (ANOVA). In this research, ANOVA tests were performed to find the significant parameters that affect the fresh properties of SCLC. The results of ANOVA for fresh properties of SCLC are presented in Table 5. In this table, the $p$ values display the significance of the independent variable (MS, CS and $w / b$ ) on the fresh properties of SCLC. The $p$ value less than 0.05 denotes that the factors MS (\%), CS (\%) and $W / b$ ratio significantly affect the fresh properties of the produced SCLCs.

\section{Measured hardened SCLC properties and statistical analysis}

Table 6 illustrates the experimental results of the compressive strength, modulus of elasticity and water absorption for SCLCs.

Table 5 Statistical evaluation of fresh properties of SCLC

\begin{tabular}{|c|c|c|c|c|}
\hline Dependent variable & $\begin{array}{l}\text { Independent vari- } \\
\text { able }\end{array}$ & $d f$ & $p$ value & Significance \\
\hline \multirow{5}{*}{$\begin{array}{l}\text { Slump flow diam- } \\
\text { eter }\end{array}$} & Micro-silica & 1 & 0.005 & Yes \\
\hline & $\begin{array}{l}\text { Colloidal nano- } \\
\text { silica }\end{array}$ & 3 & 0.000 & Yes \\
\hline & $w / b$ & 1 & 0.004 & Yes \\
\hline & Error & 10 & - & - \\
\hline & Total & 15 & - & - \\
\hline \multirow{5}{*}{$\begin{array}{l}\text { T50 slump flow } \\
\text { time }\end{array}$} & Micro-silica & 1 & 0.002 & Yes \\
\hline & $\begin{array}{l}\text { Colloidal nano- } \\
\text { silica }\end{array}$ & 3 & 0.001 & Yes \\
\hline & $w / b$ & 1 & 0.003 & Yes \\
\hline & Error & 10 & - & - \\
\hline & Total & 15 & - & - \\
\hline \multirow[t]{5}{*}{ V-funnel time } & Micro-silica & 1 & 0.004 & Yes \\
\hline & $\begin{array}{l}\text { Colloidal nano- } \\
\text { silica }\end{array}$ & 3 & 0.001 & Yes \\
\hline & $w / b$ & 1 & 0.001 & Yes \\
\hline & Error & 10 & - & - \\
\hline & Total & 15 & - & - \\
\hline \multirow[t]{5}{*}{ J-ring diameter } & Micro-silica & 1 & 0.000 & Yes \\
\hline & $\begin{array}{l}\text { Colloidal nano- } \\
\text { silica }\end{array}$ & 3 & 0.000 & Yes \\
\hline & $w / b$ & 1 & 0.005 & Yes \\
\hline & Error & 10 & - & - \\
\hline & Total & 15 & - & - \\
\hline \multirow[t]{5}{*}{ U-box (h2-h1) } & Micro-silica & 1 & 0.000 & Yes \\
\hline & $\begin{array}{l}\text { Colloidal nano- } \\
\text { silica }\end{array}$ & 3 & 0.000 & Yes \\
\hline & $w / b$ & 1 & 0.000 & Yes \\
\hline & Error & 10 & - & - \\
\hline & Total & 15 & - & - \\
\hline
\end{tabular}

Moreover, Fig. 3 indicates the normalized values of the modulus of elasticity and the compressive strength and Fig. 4 shows the normalized water absorption of SCLCs with respect to the control specimen at each $w / b$ ratio.

\section{Compressive strength}

As shown in Table 6 and Fig. 3, the replacement of cement with MS and CS increased the 28-day compressive strength of SCLC.

The compressive strength ranged from 39.35 to $51.7 \mathrm{MPa}$ and 28.8 to $37.1 \mathrm{MPa}$ for $w / b$ ratios of 0.35 and 0.45 , respectively. The minimum values of compressive strength correspond to control mixtures and maximum values correspond to $10 \% \mathrm{MS}$ and $3 \% \mathrm{CS}$ mixtures at both $w / b$ ratios. According to these results, the analysis of variance (ANOVA) for the 28-day compressive strength was performed and the results are presented in Table 7.

The $p$ value which is less than 0.05 denotes that the factors MS (\%), CS (\%) and W/b ratio significantly affect the 28-day compressive strength of the SCLC mixtures. Figure 5 shows the main effects plot for the 28-day compressive strength of SCLC considering the factors $W / b$ ratio, MS (\%) and CS (\%). It can be detected that the compressive strength decreases as the $w / b$ level changes from the low (0.35) to the high (0.45) level. This is due to the improvement of the SCLC porosity (Hover 2011). Moreover, the main effects plot shows the compressive strength increases as MS level changes from 0 to $10 \%$. Figure 3 shows that

Table 6 Experimental results of hardened SCLCs

\begin{tabular}{lccl}
\hline Mix & $\begin{array}{l}\text { Compressive } \\
\text { strength (MPa) }\end{array}$ & $\begin{array}{l}\text { Modulus of elas- } \\
\text { ticity (MPa) }\end{array}$ & $\begin{array}{l}\text { Water } \\
\text { absorption } \\
(\%)\end{array}$ \\
\hline L-M0C0 & $39.35(1.1)$ & $23.05(0.34)$ & 4.34 \\
L-M0C1 & $43.8(2.1)$ & $24.7(0.46)$ & 3.98 \\
L-M0C3 & $46.9(0.4)$ & $25.9(0.6)$ & 3.87 \\
L-M0C5 & $46(1.3)$ & $25.45(1)$ & 3.88 \\
L-M10C0 & $43.7(0.6)$ & $24.70(0.36)$ & 4.08 \\
L-M10C1 & $48.5(1.05)$ & $26.15(0.4)$ & 3.45 \\
L-M10C3 & $51.7(1.3)$ & $27(0.6)$ & 3.23 \\
L-M10C5 & $47.15(0.9)$ & $25.80(0.8)$ & 3.29 \\
H-M0C0 & $28.8(1)$ & $19.8(0.3)$ & 5.34 \\
H-M0C1 & $32.4(0.6)$ & $21.2(0.17)$ & 4.81 \\
H-M0C3 & $34.85(1)$ & $22.1(0.64)$ & 4.27 \\
H-M0C5 & $33.8(0.7)$ & $21.45(0.95)$ & 4.38 \\
H-M10C0 & $31.5(1.15)$ & $20.75(0.6)$ & 4.74 \\
H-M10C1 & $34.7(0.5)$ & $22.05(0.42)$ & 4.1 \\
H-M10C3 & $37.1(0.8)$ & $22.50(0.68)$ & 3.56 \\
H-M10C5 & $33.9(1.5)$ & $22.00(0.37)$ & 3.62 \\
\hline
\end{tabular}

The numbers in parentheses are standard deviations. Standard deviations of water absorption were negligible 
Fig. 3 Normalized values of the compressive strength and modulus of elasticity of SCLC with respect to the control specimen in each $w / b$ ratio

Fig. 4 Normalized water absorption of SCLCs with respect to the control specimen in each $w / b$ ratio
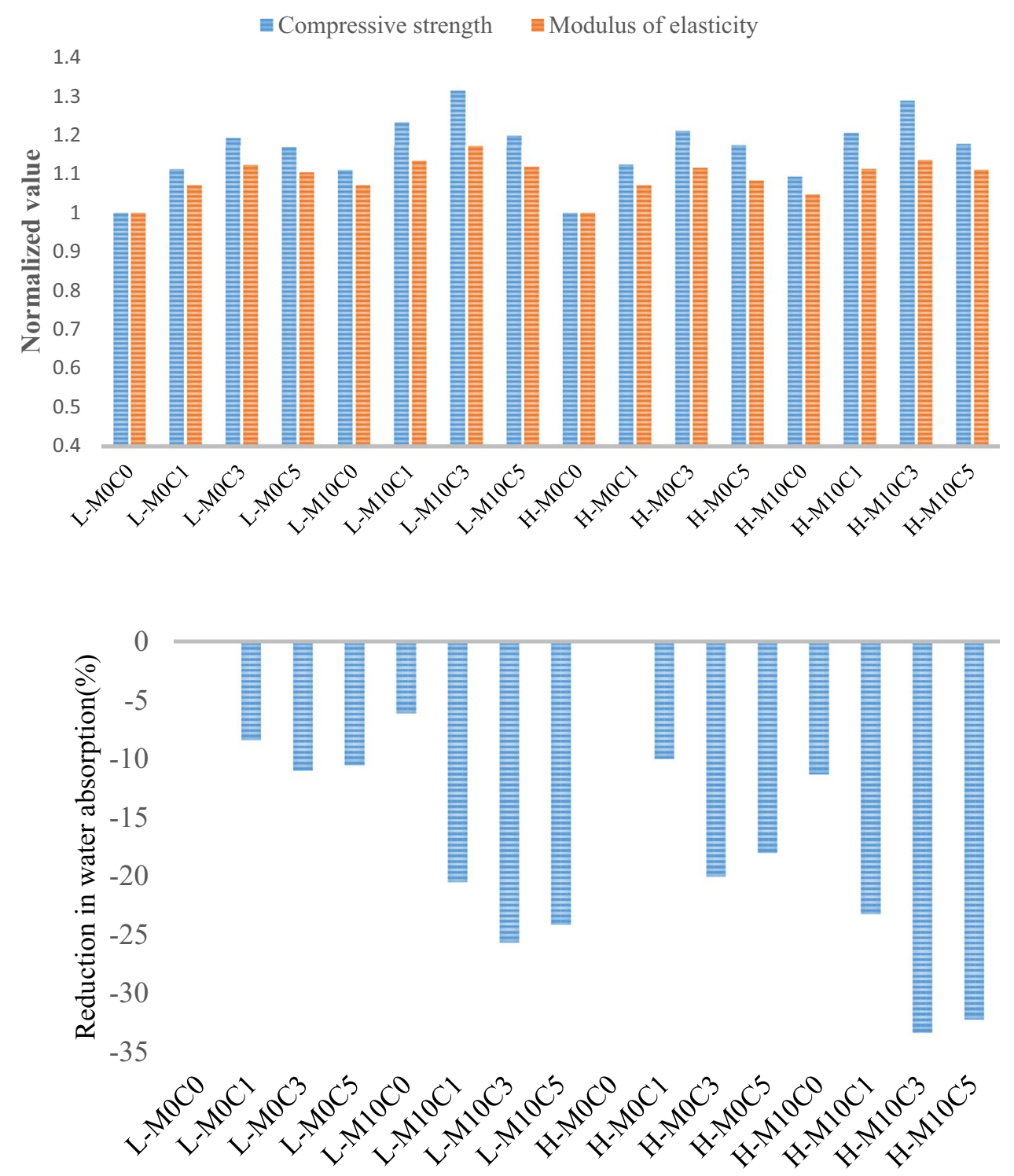

Table 7 The analysis of variance for 28-day compressive strength of SCLCs

\begin{tabular}{lrrrrrr}
\hline Source & $d f$ & \multicolumn{1}{c}{ Seq SS } & \multicolumn{1}{c}{ Adj SS } & Adj MS & \multicolumn{1}{c}{$F$} & \multicolumn{1}{c}{$p$} \\
\hline$w / b$ & 1 & 1876.88 & 1876.88 & 1876.88 & 2302.47 & 0.000 \\
MS & 1 & 93.66 & 93.66 & 93.66 & 114.90 & 0.000 \\
CS & 3 & 285.79 & 285.79 & 95.26 & 116.86 & 0.000 \\
$w / b \times$ MS & 1 & 10.97 & 10.97 & 10.97 & 13.46 & 0.001 \\
$w / b \times$ CS & 3 & 6.02 & 6.02 & 2.01 & 2.46 & 0.080 \\
MS $\times$ CS & 3 & 18.82 & 18.82 & 6.27 & 7.69 & 0.001 \\
$w / b \times$ MS $\times$ CS & 3 & 1.09 & 1.09 & 0.36 & 0.45 & 0.721 \\
Error & 32 & 26.09 & 26.09 & 0.82 & & \\
Total & 47 & 2319.31 & & & & \\
\hline
\end{tabular}

the replacement of cement with $10 \%$ MS in binary mixes improved the compressive strength by about $11 \%$ and $9.4 \%$ compared to the control mixtures at the $w / b$ ratios of 0.35 and 0.45 , respectively. This can be because by using MS the aggregate-paste bond was enhanced and the microstructure improved (Siddique 2011). As seen in Fig. 5, the 28-day compressive strength of SCLC increases by the replacement of CS up to $3 \%$ and then decreases. The same trend was 
Fig. 5 Main effect plots for the 28-day compressive strength of SCLC

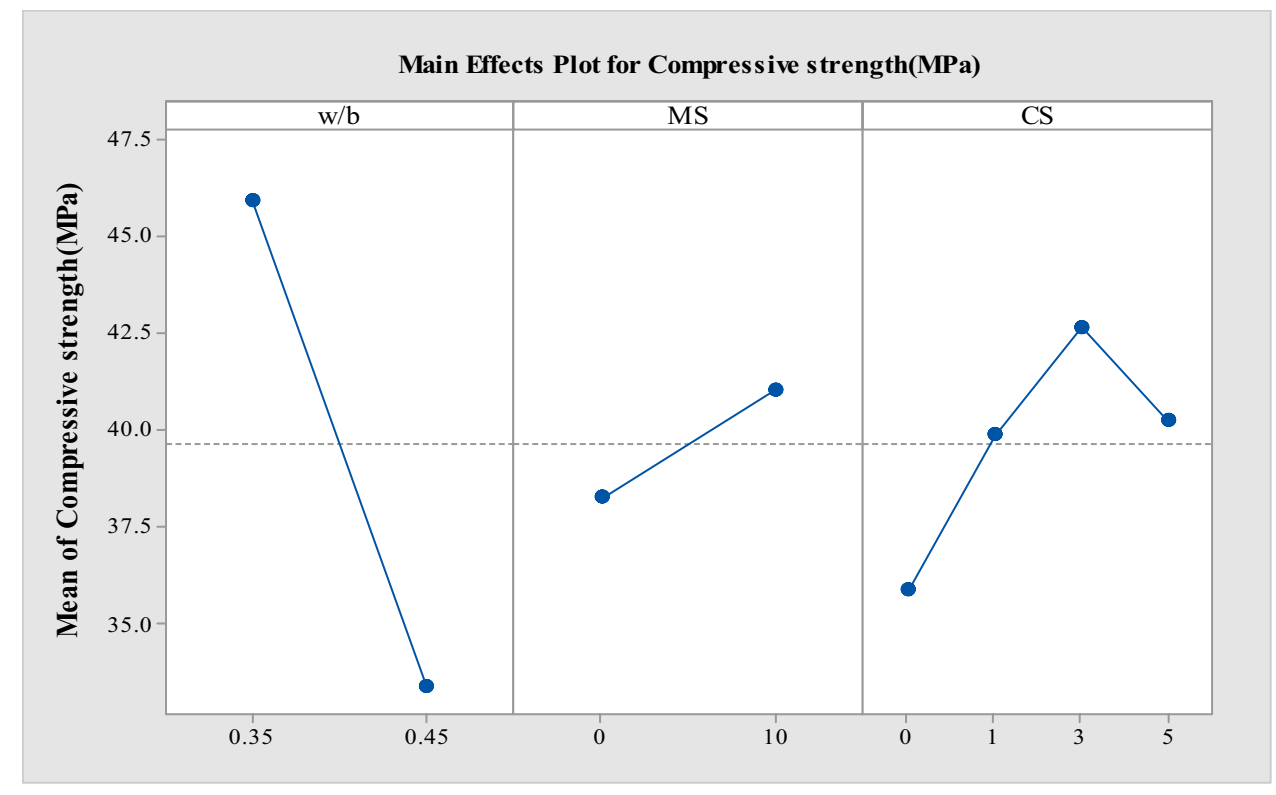

reported by previous studies (Chithra et al. 2016; Amin and Abu El-Hassan 2015). Figure 3 indicates that the replacement of cement with 1, 3 and 5\% CS increased the compressive strength by approximately $11.3,19.1$ and $16.8 \%$ and $12.5,21$ and $17.3 \%$ in comparison with control mixtures at the $w / b$ ratios of 0.35 and 0.45 , respectively. The increase of the compressive strength can be due to the addition of $\mathrm{SiO}_{2}$ nanoparticles into the concrete that improves its microstructure (Najigivi et al. 2013). The reduction of the compressive strength after the optimum amount of CS (3\%) may be attributed to the large agglomeration of nanoparticles, which led to formation of the weak zones all over the microstructure of the cementitious composite (Nili and Ehsani 2015; Kong et al. 2012).

As can be seen in Fig. 3, the replacement of cement with $10 \% \mathrm{MS}$ and $3 \% \mathrm{CS}$ showed the maximum compressive strength, which were approximately $31.4 \%$ and $28.8 \%$ more than that of control mixes at the $w / b$ ratios of 0.35 and 0.45 , respectively. Figure 6 displays the interaction plots between the three factors for the compressive strength of SCLCs. There is no interaction between the factors when the lines are exactly parallel, and the nonparallel lines show an interaction between the factors. As can be seen in Fig. 6, the interaction that occurred between MS and CS factors for the compressive strength is indicated by nonparallel lines. In other words, the effects of the combined addition of MS and $\mathrm{CS}$ on the compressive strength are altered by changing the level of CS from 3 to 5\%. It is clear in Figs. 3 and 6 that the combined addition of MS and CS, ternary mixtures provides better performance than adding only one of them. The obtained results are in good agreement with previous studies (Jalal et al. 2012; Li et al. 2017).
A model is developed for the 28-day compressive strength using multiple regression analysis based on the significant parameters in the ANOVA results.

Compressive strength $(\mathrm{MPa})$

$$
\begin{aligned}
& =81.9835-115.5 w / b+1.16555 \mathrm{MS}+1.09068 \mathrm{CS} \\
& \quad-1.9125 w / b \times \mathrm{MS}-0.0538559 \mathrm{MS} \times \mathrm{CS}, \\
& R^{2}=91.14 \% . \\
& \text { Modulus of elasticity }
\end{aligned}
$$

The 28-day modulus of elasticity of the $\mathrm{SClC}$ mixtures is presented in the second column of Table 8 . As can be seen, the modulus of elasticity ranged from 23.05 to $27 \mathrm{MPa}$ and 19.8 to $22 \mathrm{MPa}$ for the $w / b$ ratios of 0.35 and 0.45 , respectively. The results of ANOVA for the 28-day modulus of elasticity are presented in Table 8 . It is observed that MS $(p=0.000), \mathrm{CS}(p=0.000)$ and $w / b(p=0.000)$ with $p$ values $\leq 0.05$ for $95 \%$ confidence level are statically important for the modulus of elasticity.

Figure 7 shows the main effects plot for the 28-day modulus of elasticity of SCLC considering the factors $W / b$ ratio, MS (\%) and CS (\%). The trend in the modulus of elasticity was approximately similar to the trend of compressive strength. As can be seen in Fig. 7, the modulus of elasticity of SCLCs decreases as $w / b$ level changes from the low $(0.35)$ to the high (0.45) level. This is due to the improvement of the SCLC porosity in the high $w / b$ ratio. This result is in line with those reported for NWSCC (Beygi et al. 2013, 2014) and SCLC (Karamloo et al. 2016b). As shown in Table 6, the increase of MS level from 0 to $10 \%$ increased the modulus of elasticity from 23.05 to $27 \mathrm{MPa}$ and from 19.8 to $22.5 \mathrm{MPa}$ in $w / b$ ratios of 0.35 and 0.45 , respectively. These observations 
Fig. 6 The interaction effect plots for the 28-day compressive strength of SCLC

Table 8 The Analysis of variance for the 28-day modulus of elasticity of SCLC

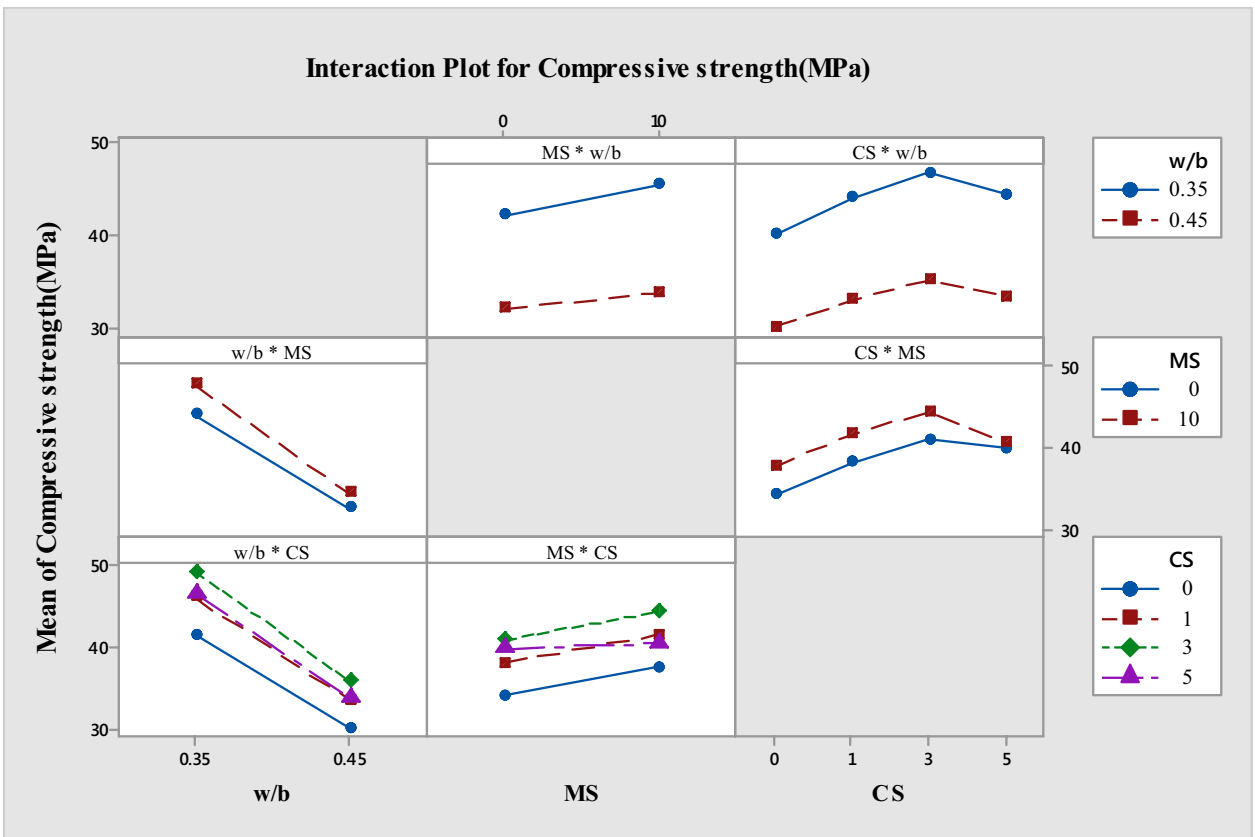

\begin{tabular}{lllllll}
\hline Source & $d f$ & Seq SS & Adj SS & Adj MS & $F$ & $p$ \\
\hline$w / b$ & 1 & 179.027 & 179.027 & 179.027 & 614.03 & 0.000 \\
MS & 1 & 9.992 & 9.992 & 9.992 & 34.27 & 0.000 \\
CS & 3 & 33.563 & 33.562 & 11.187 & 38.37 & 0.000 \\
$w / b \times$ MS & 1 & 0.608 & 0.608 & 0.608 & 2.08 & 0.159 \\
$w / b \times$ CS & 3 & 0.471 & 0.471 & 0.157 & 0.54 & 0.660 \\
MS $\times$ CS & 3 & 1.341 & 1.341 & 0.447 & 1.53 & 0.225 \\
$w / b \times$ MS $\times$ CS & 3 & 0.428 & 0.428 & 0.143 & 0.49 & 0.693 \\
Error & 32 & 9.330 & 9.330 & 0.292 & & \\
Total & 47 & 234.757 & & & & \\
\hline
\end{tabular}

Fig. 7 Main effect plots for the 28-day modulus of elasticity of SCLC

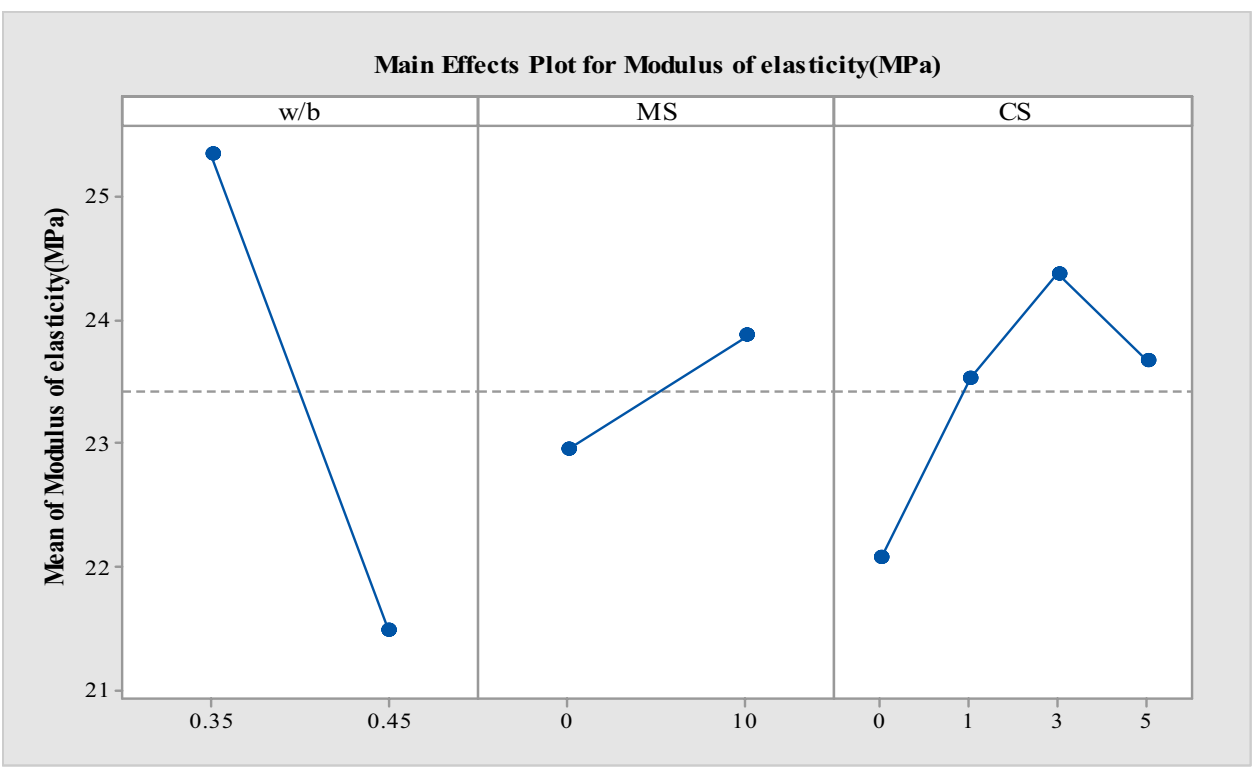


are in good agreement with the previous findings (Mazloom et al. 2004). Figure 7 shows that the modulus of elasticity of SCLC increases by the replacement of CS up to 3\% and then decreases. The same trend has been reported by Amin and El-Hassan (2015). As can be seen in Fig. 3, the mixes with 1, 3 and 5\% CS showed an increase in the modulus of elasticity of $7.1,12.3,10.14$ and $7 \%, 11.6 \%$ and $8.3 \%$ in $w / b$ ratios of 0.35 and 0.45 , respectively. The increase of the modulus of elasticity in the mixes containing CS is due to the compactness of the paste bond with aggregates (Saloma et al. 2013). Figure 8 depicts the interaction plots between the three factors for modulus of elasticity of SCLCs. The improvement of the modulus of elasticity in ternary mixes, the replacement of cement with both MS and CS, was better than that of the binary and the control mixes. So, the replacement of cement with 10\% MS and 3\% CS showed the maximum modulus of elasticity, which was approximately $17.14 \%$ and $13.6 \%$ more than that of control mixes at the $w / b$ ratios of 0.35 and 0.45 , respectively (See Fig. 3).

As can be seen in Fig. 8, the interaction that occurred between the MS and CS factors for the modulus of elasticity is indicated by nonparallel lines. In other words, the effects of these factors on the modulus of elasticity are altered by changing the level of CS from 3 to 5\%. A mathematical model is presented for the 28-day modulus of elasticity using multiple regression analysis based on the significant parameters in the ANOVA results.
Figure 9 displays the compressive strength versus the modulus of elasticity in the tested mixtures and also in some other researches. Previous studies have proposed many relations between compressive strength and the modulus of elasticity for NC, NWSCC and SCLC. However, there are considerable contradictions among the previous researches. Some researchers have reported that NC and NWSCC have the same modulus of elasticity (Pentti 1999). Some other researchers have expressed that NWSCC has lower modulus of elasticity than NC (Holschmacher and Klug 2002; Klug and Holschemacher 2003). Persson (2001) expressed that when the strength remains constant, there is a little difference between the modulus of elasticity of NWSCC and NC. Ashtiani et al. (2013) expressed that the modulus of elasticity of high strength self-compacting concrete (HSSCC) becomes lower than that of high strength normal concrete (HSNC). Parra et al. (2011) showed that lower stiffness of paste caused modulus of elasticity of NWSCC to become only $2 \%$ lower than NC.

In the present paper, the relation between modulus of elasticity and the compressive strength of SCLC was determined in the form of a power function as follows:

$$
\begin{aligned}
E & =3703 \sqrt{ } f_{\mathrm{c}}, \\
R^{2} & =0.954
\end{aligned}
$$

where $E$ is the modulus of elasticity (MPa) and $f_{\mathrm{c}}$ is the cubic compressive strength (MPa) of SCLC. As can be seen

Modulus of elasticity $(\mathrm{MPa})=37.7484-38.625 w / b+0.09125 \mathrm{MS}+0.292373 \mathrm{CS}$

$$
R^{2}=86.96 \%
$$

Fig. 8 The interaction effect plots for the 28-day modulus elasticity of SCLC

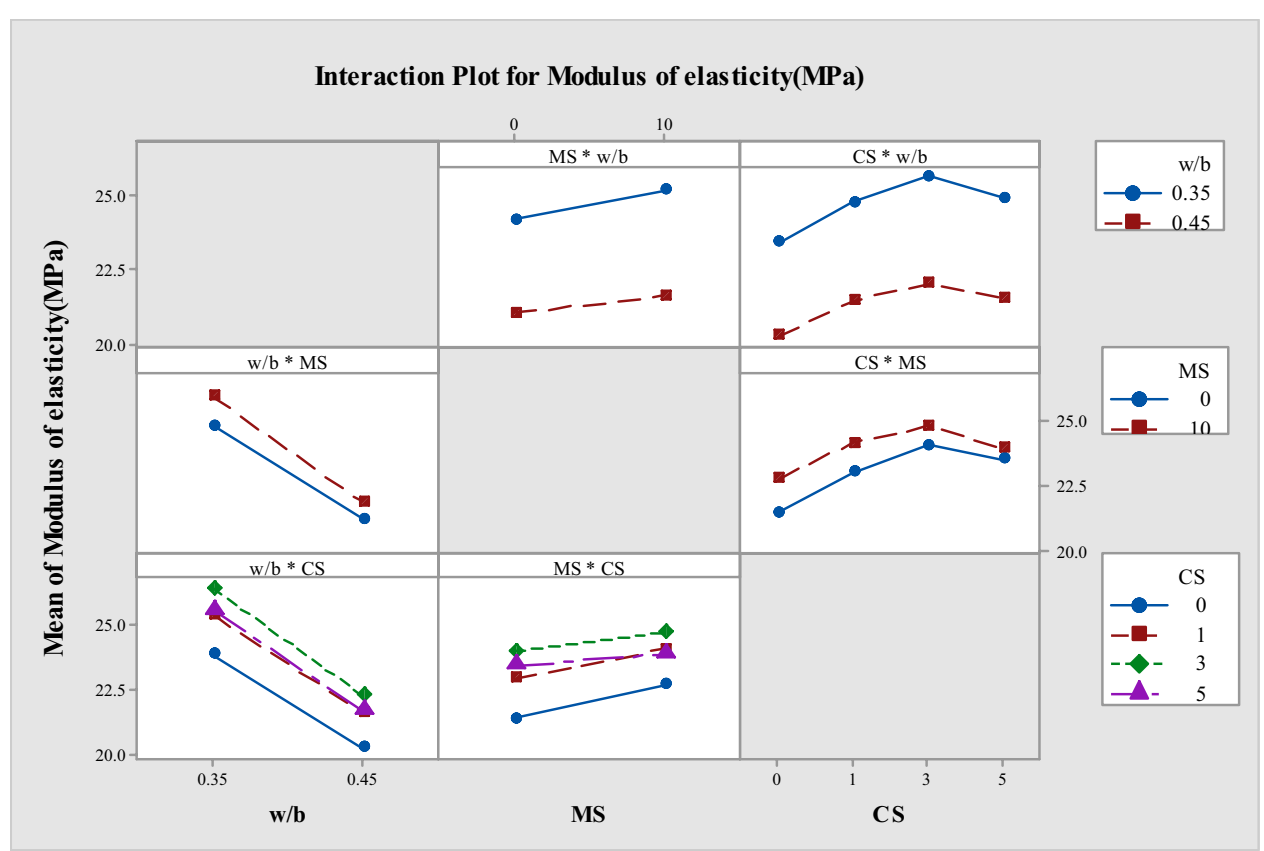


Fig. 9 Compressive strength versus the modulus of elasticity in the tested mixtures and also in some other researches

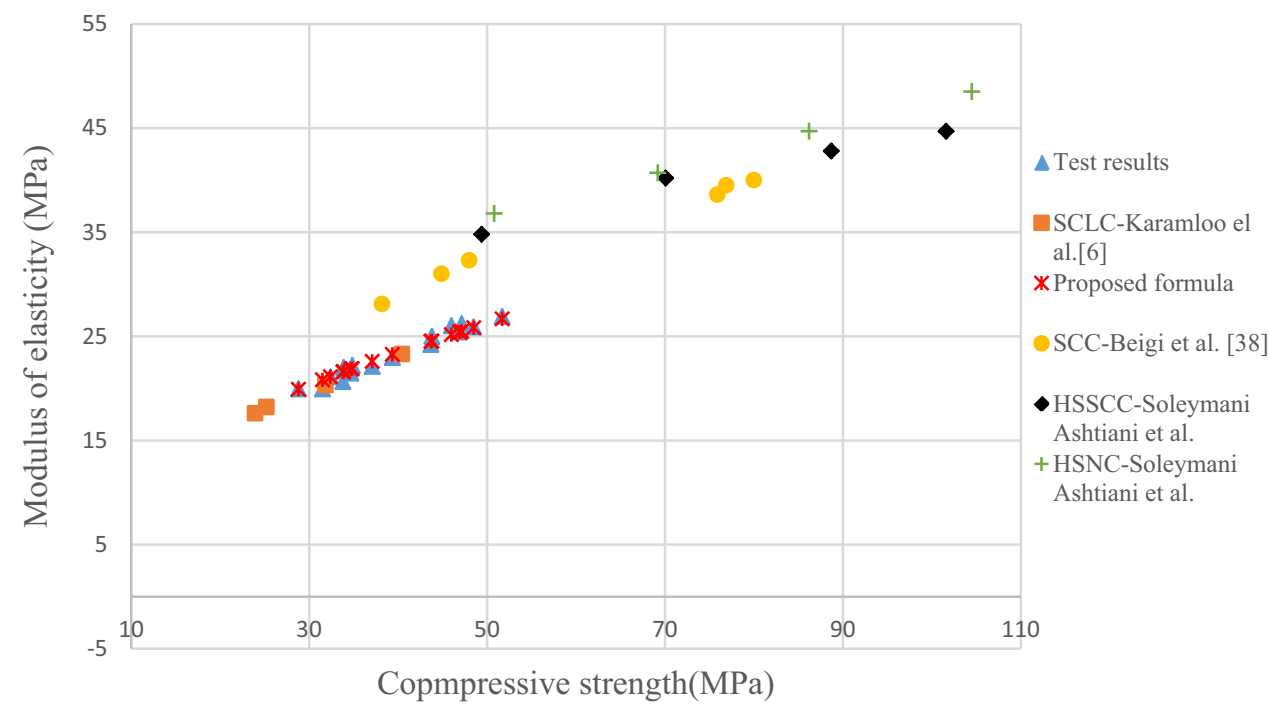

in Fig. 9, the modulus of elasticity of SCLC is lower than those of NWSCC and NC. This difference can be due to the type of aggregate, the volume of aggregate and the volume of paste in these types of concrete.

\section{Water absorption}

Water absorption is among the properties that are connected to concrete durability (Lukic et al. 2015). Moreover, Schutter and Audenaert (2004) stated that the water absorption could indicate the amount of pore volume of concrete; however, the permeability of the concrete cannot be indicated.

The third column of Table 6 shows the water absorption of SCLC mixtures. In addition, Fig. 4 displays the normalized water absorption of SCLCs with respect to the control mixes in each $w / b$ ratio. It can be seen that the 28-day water absorption ranges from 3.23 to $5.34 \%$. All the SCLC mixes containing MS and CS showed lower water absorption in comparison to the control mixes at both $w / b$ ratios. Table 9 shows the results of ANOVA analysis for water absorption.

It can be deduced from Table 9 for water absorption that the factors MS $(p=0.000), \operatorname{CS}(p=0.000)$ and $w / b$
( $p=0.000)$ with $p$ values $\leq 0.05$ for $95 \%$ confidence level would be statically significant. An analysis of water absorption of SCLC at both $w / b$ ratios shows that the replacement of cement with MS and CS decreases the quantity of water absorbed by hardened SCLC at the age of 28 days. Chithra et al. (2016) reported that nano-silica enhanced the pore structure of the concrete and reduced the water absorption of concrete. Figure 10 shows the main effects plot for the 28-day water absorption of SCLC considering the factors $\mathrm{W} / \mathrm{b}$ ratio, MS (\%) and CS (\%).

Figure 11 shows the interaction plots between the three factors for water absorption of SCLCs. The use of blended MS and CS in ternary mixes seemed to be the most effective one in the reduction of water absorption. For instance, the lowest water absorption was measured for SCLC with the blending of $10 \% \mathrm{MS}$ and $3 \% \mathrm{CS}$ in the $w / b$ ratio of 0.35 ; it was approximately $34 \%$ less than that of the control mix. This can be attributed to the pozzolanic and filler activities of MS and CS, which led to a denser and more compacted microstructure. It is clear that when the cement was replaced with both MS and CS (ternary mixes), MS
Table 9 The analysis of variance for the 28-day water absorption of SCLC

\begin{tabular}{lllllll}
\hline Source & $d f$ & Seq SS & Adj SS & Adj MS & $F$ & $p$ \\
\hline$w / b$ & 1 & 4.1536 & 4.1536 & 4.1536 & 450.26 & 0.000 \\
MS & 1 & 4.3200 & 4.3200 & 4.3200 & 468.29 & 0.000 \\
$\mathrm{CS}$ & 3 & 5.9805 & 5.9805 & 1.9935 & 216.10 & 0.000 \\
$w / b \times \mathrm{MS}$ & 1 & 0.1102 & 0.1102 & 0.1102 & 11.95 & 0.002 \\
$w / b \times \mathrm{CS}$ & 3 & 0.4833 & 0.4833 & 0.1611 & 17.46 & 0.000 \\
$\mathrm{MS} \times \mathrm{CS}$ & 3 & 0.1155 & 0.1155 & 0.0385 & 4.17 & 0.013 \\
$w / b \times \mathrm{MS} \times \mathrm{CS}$ & 3 & 0.0282 & 0.0282 & 0.0094 & 1.02 & 0.397 \\
Error & 32 & 0.2952 & 0.2952 & 0.0092 & & \\
Total & 47 & 15.4866 & & & & \\
\hline
\end{tabular}


Fig. 10 Main effect plots for the 28-day water absorption of SCLC

Fig. 11 The interaction effect plots for the 28-day water absorption of SCLC
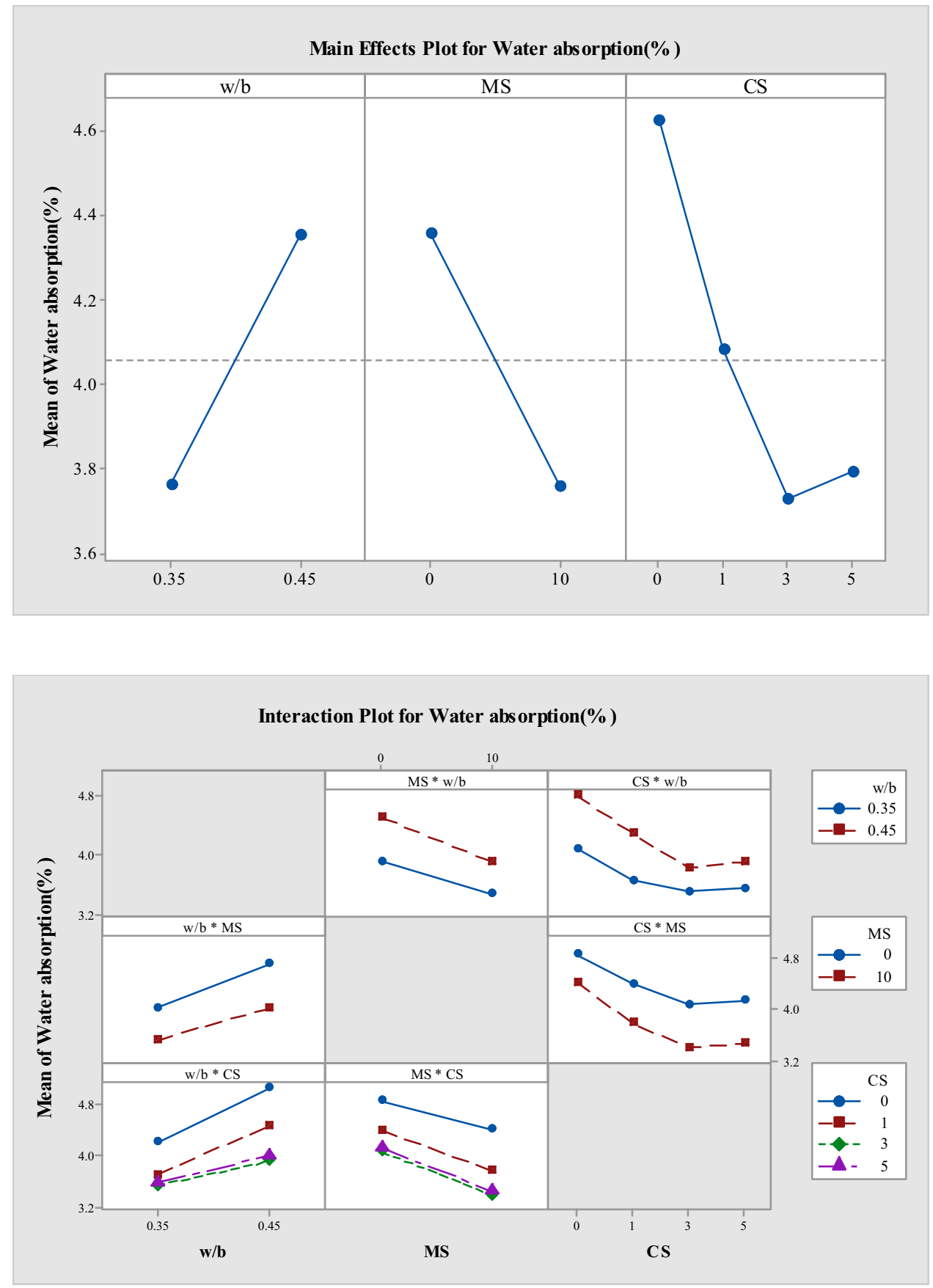

particles filled the voids between the cement grains and NS filled into the voids between MS ( $\mathrm{Li}$ et al. 2017).

The microstructure observations of the SCLCs could provide important information for evaluating the effects of additives on the properties of concrete. For example, Fig. 12 shows the scanning electron microscope (SEM) image of SCLCs. It can be observed that SCLCs with $1 \%$ CS have denser microstructure than the control specimen.
A mathematical model was developed for the 28-day water absorption using multiple regression analysis based on the significant parameters in the ANOVA results.

Water absorption (\%)

$$
\begin{aligned}
= & 1.07585+8.95692 w / b+0.0259972 \mathrm{MS} \\
& +0.242401 \mathrm{CS}-0.191667 w / b \times \mathrm{MS} \\
& -0.940113 w / b \times \mathrm{CS}-0.00414689 \mathrm{MS} \times \mathrm{CS}
\end{aligned}
$$

$R^{2}=85.68 \%$. 
Fig. 12 Comparing the microstructures of the mixes containing no additives (left) and $1 \%$ of CS (right)

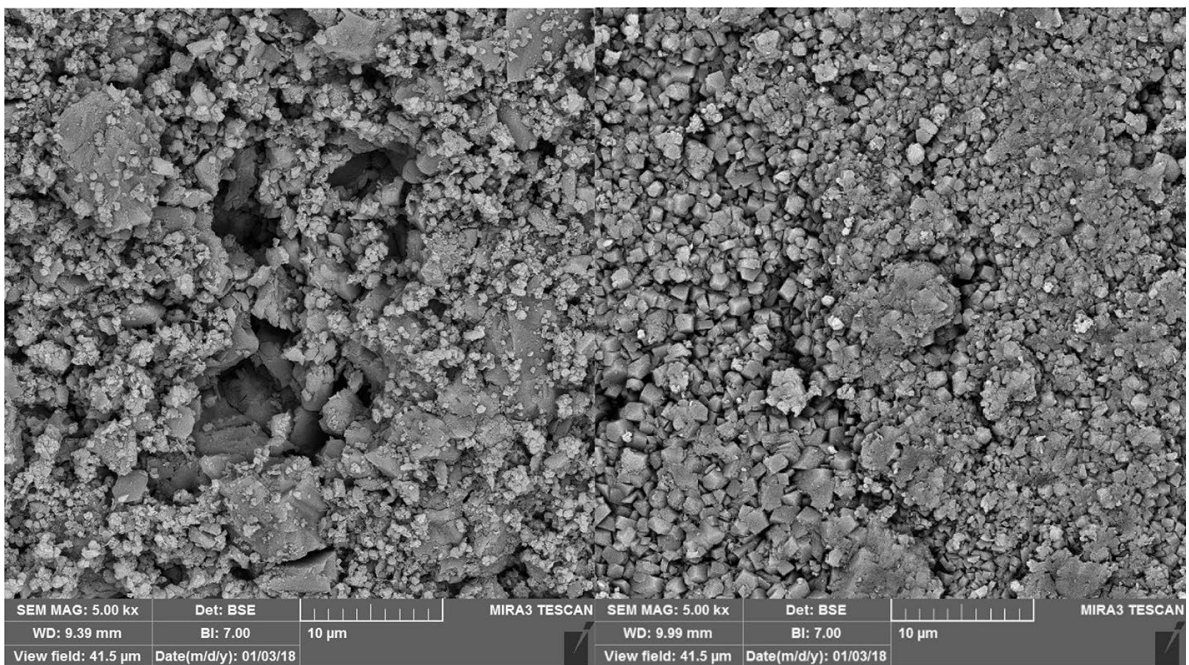

\section{Multi-response optimization}

The response optimization technique, by Minitab, was used to determine an optimal solution. The optimized properties by a response optimization technique are known as the desirability $(D)$ function. In this technique, all predictors of responses are required to be converted into an individual desirability function $(d)$, which is in the range of $0-1$ and must be optimized for all the responses (Ashenai Ghasemi et al. 2017; George et al. 2005). More explanation about this technique can be found in the book by George et al. (2005).

Figure 13 shows the results of the optimal condition. As can be seen, to maximize the compressive strength and the modulus of elasticity and also to minimize the water absorption at the same time, with maximum composite desirability $(D=0.9342), w / b$ must be adjusted at 0.35 , MS at $10 \%$, and $\mathrm{CS}$ at $3 \%$. Moreover, the composite desirability $(D=0.9342)$ was nearly close to 1 ; in this case it can be concluded that the settings appeared to proved the favorite results for all the responses.

\section{Conclusions}

In this paper, the influence of different replacement levels of the cement by micro-silica (MS) and colloidal nano-silica (CS) on the behavior of self-compacting lightweight concrete (SCLC) has been investigated. For this purpose, an optimization technique, in which the mathematical modeling and full factorial design along with the desirability function method were integrated, was used. The following conclusions can be presented:

- Although the replacement of cement with MS and CS decreased the flowability of SCLC and also in some cases

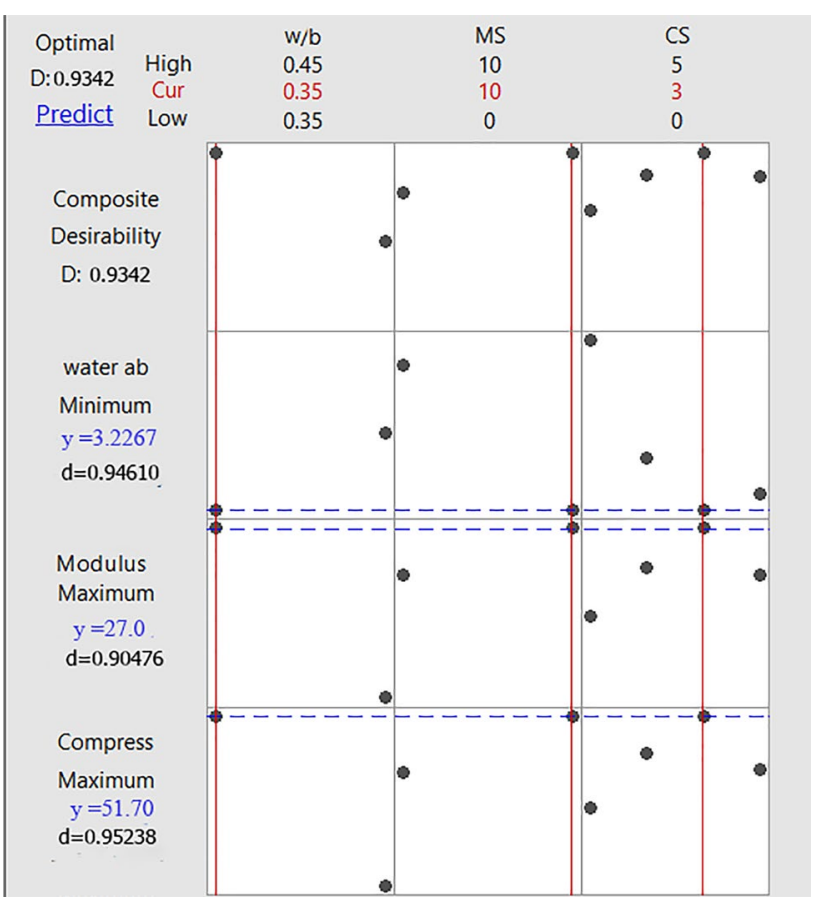

Fig. 13 The results of the desirability function analysis

led to the use of a high dosage of superplasticizer (SP), the results show that almost all of the fresh properties of SCLCs were in the range of EFNARC. The decrease in flowability of SCLCs could be attributed to the high water demand of MS and CS.

- According to ANOVA analysis, $w / b$, MS and CS significantly influenced the compressive strength and modulus of elasticity of SCLC. The main effect plots and interaction plots of compressive strength and the modulus of elasticity at the age of 28 days indicated that these properties decreased with the increase of $w / b$ ratio and 
increased with increase in the content of MS and CS, but the optimum amount of CS (regardless of MS content and $w / b$ ratio) was $3 \%$. Moreover, the interaction plots and ANOVA tables of the mentioned properties depict that the interaction occurred between MS and CS factors for the compressive strength and the modulus of elasticity.

- The comparison of the modulus of elasticity with the previous studies showed that at a given compressive strength, the modulus of elasticity of SCLC was lower than that of normal weigh self-compacting concrete (NWSCC) and normal concrete (NC). This difference can be attributed to the type of aggregate, the volume of aggregate and the volume of paste in the mentioned concrete.

- The 28-day water absorption of SCLC improved with the increase in $w / b$ ratio and was reduced by the addition of MS and CS. The optimum dosage of CS was 3\%, which can be seen from the main effect plots.

- The interaction plots of the compressive strength, the modulus of elasticity and water absorption show that in all of these properties of SCLCs, the combined addition of MS and CS, ternary mixtures, provide better performance than adding only one of them. When cement was replaced with both MS and CS (ternary mixes), the filler effect and the pozzolanic activity of the particles were enhanced.

- The maximum value of compressive strength and the modulus of elasticity and the minimum value of water absorption were measured for SCLC with the blend of $10 \% \mathrm{MS}$ and $3 \% \mathrm{CS}$ in $w / b$ ratio of 0.35 . The results of the desirability function analysis in the optimization plot, with the composite desirability $(D=0.9342)$, confirmed these observations. The maximum increases for compressive strength and modulus of elasticity were $31 \%$ and $17 \%$, respectively. The maximum decrease for water absorption was $34 \%$.

Acknowledgements The authors wish to acknowledge the supports of the Shahid Rajaee Teacher Training University.

\section{Compliance with ethical standards}

Conflict of interest The authors declare no conflict of interest.

Open Access This article is distributed under the terms of the Creative Commons Attribution 4.0 International License (http://creativeco mmons.org/licenses/by/4.0/), which permits unrestricted use, distribution, and reproduction in any medium, provided you give appropriate credit to the original author(s) and the source, provide a link to the Creative Commons license, and indicate if changes were made.

\section{References}

Afzali-Naniz, O., \& Mazloom, M. (2018). Effects of colloidal nanosilica on fresh and hardened properties of self-compacting lightweight concrete. Journal of Building Engineering, 20, 400-410.

Amin, M., \& Abu El-Hassan, K. (2015). Effect of using different types of nano materials on mechanical properties of high strength concrete. Construction and Building Materials, 80, 116-124.

Ashenai Ghasemi, F., Daneshpayeh, S., \& Ghasemi, I. (2017). Multiresponse optimization of impact strength and elongation at break of nanocomposites based on polypropylene/polyethylene binary polymer matrix in the presence of titanium dioxide nanofiller. Journal of Elastomers and Plastics, 49(8), 633-649.

Ashtiani, M. S., Scott, A. N., \& Dhakal, R. P. (2013). Mechanical and fresh properties of high-strength self-compacting concrete containing class $\mathrm{C}$ fly ash. Construction and Building Materials, 47, 1217-1224.

ASTM C 469. (2002). Standard test method for static modulus of elasticity and Poisson's ratio of concrete in compression. West Conshohocken: Annual Book of ASTM Standards.

ASTM C642-97. (2006). Standard test method for density, absorption, and voids in hardened concrete. West Conshohocken: Annual Book of ASTM Standards.

Bahadori, H., \& Hosseini, P. (2012). Reduction of cement consumption by the aid of silica nano-particles (investigation on concrete properties). Journal of Civil Engineering and Management, 18(3), 416-425.

Bernal, J., Reyes, E., Massana, J., León, N., \& Sánchez, E. (2018). Fresh and mechanical behavior of a self-compacting concrete with additions of nano-silica, silica fume and ternary mixtures. Construction and Building Materials, 160, 196-210.

Beygi, M. H. A., Kazemi, M. T., Amiri, J. V., Nikbin, I. M., Rabbanifar, S., \& Rahmani, E. (2014). Evaluation of the effect of maximum aggregate size on fracture behavior of self compacting concrete. Construction and Building Materials, 55, 202-211.

Beygi, M. H. A., Nikbin, I. M., \& Amiri, J. V. (2013). The effect of water to cement ratio on fracture parameters and brittleness of self-compacting concrete. Materials and Design, 50, 267-276.

BS EN 12390. (2000). Testing hardened concrete, method of determination of compressive strength of concrete cubes. UK: British Standards Institution.

Chithra, S., Kumar, S. R. R. S., \& Chinnaraju, K. (2016). The effect of colloidal nano-silica on workability, mechanical and durability properties of high performance concrete with copper slag as partial fine aggregate'. Construction and Building Materials, 113, 794-804.

EFNARC. (2002). Specification and guidelines for self-compacting concrete. Norfolk: European Federation for Specialist Construction Chemicals and Concrete Systems.

Felekoglu, B. S., \& Türkel, B. B. (2007). Effect of water/cement ratio on the fresh and hardened properties of self-compacting concrete. Building and Environment, 42(4), 1795-1802.

George, E., Hunter, J. S., \& Hunter, W. G. (2005). Statistics for experimenters: design, innovation and discovery (4th ed.). New York: Wiley.

Güneyisi, E., Gesoglu, M., Azez, O. A., \& Öznur, H. O. (2016). Effect of nano silica on the workability of self-compacting concretes having untreated and surface treated lightweight aggregates. Construction and Building Materials, 115, 371-380.

Güneyisi, E., Gesoł̣lu, M., Booya, E., \& Mermerdaş, K. (2015). Strength and permeability properties of self-compacting concrete with cold bonded fly ash lightweight aggregate. Construction and Building Materials, 74, 17-24.

Holschmacher, K., \& Klug, Y. (2002). A database for the evaluation of hardened properties of SCC. Lacer, 7, 123-134. 
Hosseini, P., Booshehrian, A., \& Farschi, S. (2010). Influence of nano- $\mathrm{SiO}_{2}$ addition on microstructure and mechanical properties of cement mortars for ferrocement. Transportation Research Record, 2141, 15-20.

Hosseinpourpia, R., Varshoee, A., Soltani, M., Hosseini, P., \& Tabari, H. Z. (2012). Production of waste bio-fiber cementbased composites reinforced with nano- $\mathrm{SiO}_{2}$ particles as a substitute for asbestos cement composites. Construction and Building Materials, 31, 105-111.

Hover, K. C. (2011). The influence of water on the performance of concrete'. Construction and Building Materials, 25(7), 3003-3013.

Jalal, M., Mansouri, E., Sharifipour, M., \& Pouladkhan, A. R. (2012). Mechanical, rheological, durability and microstructural properties of high performance self-compacting concrete containing $\mathrm{SiO}_{2}$ micro and nanoparticles. Materials and Design, 34, 389-400.

Jalal, M., Pouladkhan, A., Harandi, O. F., \& Jafari, D. (2015). Comparative study on effects of class F fly ash, nano silica and silica fume on properties of high performance self compacting concrete. Construction and Building Materials, 94, 90-104.

Karamloo, M., Mazloom, M., \& Payganeh, G. (2016a). Influences of water to cement ratio on brittleness and fracture parameters of self-compacting lightweight concrete'. Engineering Fracture Mechanics, 168, 227-241.

Karamloo, M., Mazloom, M., \& Payganeh, G. (2016b). Effects of maximum aggregate size on fracture behaviors of self-compacting lightweight concrete. Construction and Building Materials, 123, 508-515.

Karamloo, M., Mazloom, M., \& Payganeh, G. (2017). Effect of size on nominal strength of self-compacting lightweight concrete and self-compacting normal weight concrete: a stress-based approach. Materials Today Communication, 13, 36-45.

Klug, Y., \& Holschemacher, K. (2003). Comparison of the hardened properties of self-compacting and normal vibrated concrete. In 3rd RILEM symposium on self compacting concrete, Reykjavik, pp. 596-605.

Kong, D., Corr, D. J., Hou, P., Yang, Y., \& Shah, S. P. (2015). Influence of colloidal silica sol on fresh properties of cement paste as compared to nano-silica powder with agglomerates in micron-scale. Cement and Concrete Composites, 63, 30-41.

Kong, D., Du, X., Wei, S., Zhang, H., Yang, Y., \& Shah, S. P. (2012). Influence of nano-silica agglomeration on microstructure and properties of the hardened cement-based materials. Construction and Building Materials, 37, 707-715.

Lachemi, M., Bae, S., Hossain, K. M. A., \& Sahmaran, M. (2009). Steel-concrete bond strength of lightweight self-consolidating concrete. Materials and Structures, 42(7), 1015-1023. (Springer).

Li, L. G., Huang, Z. H., Zhu, J., Kwan, A. K. H., \& Chen, H. Y. (2017). Synergistic effects of micro-silica and nano-silica on strength and microstructure of mortar. Construction and Building Materials, 140, 229-238.

Lukic, I., Radonjanin, V., Malesev, M. \& Bulatovic, V. (2015). Influence of mineral admixture on water absorption of lightweight aggregate concrete, 13th International scientific conference on planning, design, construction and building renewal, Novi Sad.

Mazloom, M., Allahabadi, A., \& Karamloo, M. (2017). Effect of silica fume and polyepoxide-based polymer on electrical resistivity, mechanical properties, and ultrasonic response of SCLC. Advances in Concrete Construction, 5(6), 587-611.

Mazloom, M., Homayooni, S. M., \& Miri, S. M. (2018). Effect of rock flour type on rheology and strength of self-compacting lightweight concrete. Computers and Concrete, 21(2), 199-207.

Mazloom, M., \& Mahboubi, F. (2017). Evaluating the settlement of lightweight coarse aggregate in self-compacting lightweight concrete. Computers and Concrete, 19(2), 203-210.
Mazloom, M., Ramezanianpour, A. A., \& Brooks, J. J. (2004). Effect of silica fume on mechanical properties of high-strength concrete. Cement and Concrete Composites, 26(4), 347-357.

Mazloom, M., Saffari, A., \& Mehrvand, M. (2015). Compressive, shear and torsional strength of beams made of self-compacting concrete. Computers and Concrete, 15(6), 935-950.

Mazloom, M., \& Yoosefi, M. M. (2013). Predicting the indirect tensile strength of self-compacting concrete using artificial neural networks. Computers and Concrete, 12(3), 285-301.

Montgomery, D. C. (2017). Design and analysis of experiments. Hoboken: Wiley.

Mukharjee, B. B., \& Barai, S. V. (2014). Assessment of the influence of nano-silica on the behavior of mortar using factorial design of experiments. Construction and Building Materials, 68, 416-425.

Najigivi, A., Khaloo, A., Iraji Zad, A., \& Abdul Rashid, S. (2013). Investigating the effects of using different types of $\mathrm{SiO}_{2}$ nanoparticles on the mechanical properties of binary blended concrete. Composites Part B Engineering, 54(1), 52-58.

Nili, M., \& Ehsani, A. (2015). Investigating the effect of the cement paste and transition zone on strength development of concrete containing nanosilica and silica fume. Materials and Design, 75, 174-183.

Parra, C., Valcuende, M., \& Gómez, F. (2011). Splitting tensile strength and modulus of elasticity of self-compacting concrete. Construction and Building Materials, 25(1), 201-207.

Pentti, G. H.-E. P. (1999). Properties of SCC-especially early age and long term shrinkage and salt frost resistance. In Proceedings of the 1 st International Rilem Symposium on Self-compacting Concrete, Stockholm. Rilem, Bagneux, pp. 211-225.

Persson, B. (2001). A comparison between mechanical properties of self-compacting concrete and the corresponding properties of normal concrete. Cement and Concrete Research, 31(20), 193-198.

Puentes, J., Barluenga, G., \& Palomar, I. (2015). Effect of silica-based nano and micro additions on SCC at early age and on hardened porosity and permeability. Construction and Building Material, $81,154-161$.

Ranjbar, M. M., \& Mousavi, S. Y. (2015). Strength and durability assessment of self-compacted lightweight concrete containing expanded polystyrene. Mater Struct, 48(4), 1001-1011.

Salehi, H. \& Mazloom, M. (2018a). Effect of magnetic-field intensity on fracture behaviors of self-compacting lightweight concrete, Magazine of Concrete Research, 1-15.

Salehi, H., \& Mazloom, M. (2018b). Experimental and numerical studies of crack propagation in self-compacting lightweight concrete. Modares Mechanical Engineering, 18(6), 667-678.

Saloma, Nasution, A., Imran, I., \& Abdullah, M. (2013). Experimental investigation on nanomaterial concrete. International Journal of Civil and Environmental Engineering, 13(3), 15-20.

Schutter, G. D., \& Audenaert, K. (2004). Evaluation of water absorption of concrete as a measure for resistance against carbonation and chloride migration. Materials and Structures, 37, 591-596.

Siddique, R. (2011). Resources, conservation and recycling utilization of silica fume in concrete: review of hardened properties'. Resources, Conservation and Recycling, 55(11), 923-932.

Singh, L. P., Karade, S. R., Bhattacharyya, S. K., Yousuf, M. M., \& Ahalawat, S. (2013). Beneficial role of nanosilica in cement based materials-a review. Construction and Building Materials, 47, 1069-1077.

Wu, Z., Zhang, Y., Zheng, J., \& Ding, Y. (2009). An experimental study on the workability of self-compacting lightweight concrete. Construction and Building Materials, 23(5), 2087-2092. 